Ann. Biol. anim. Bioch. Biophys., 1977, 17 (5 B), 827-849.

\title{
Evolution de l'activité de l'acétyl-CoA-carboxylase et de la lipoprotéine lipase dans le foie et les tissus adipeux du rat mâle au cours du développement après sevrage. Influence du taux de lipides de la ration.
}

par G. PASCAL, G. DURAND, J. P. MACAIRE, Eliane PENOT.

Station de Recherches de Nutrition, I.N.R.A., 78350 Jouy-en-josas.

Summary. Evolution of acetyl-CoA-carboxylase activity and of lipoprotein lipase in the liver and adipose tissues of the male rat during post-weaning development. Effect of dietary lipid content.

The specific and total activities of two key lipogenic enzymes, acetyl CoA carboxylase (ACC) and lipoproteine lipase (LPL), were studied after weaning in male rats given a diet containing 4, 12 or 21 p. 100 lipids. Specific activity was expressed in activity/g of tissue, and total activity by activity in the whole tissue.

Specific and total acetyl-CoA-carboxylase activities were studied in the liver, subcutaneous dorsal adipose tissue and perirenal adipose tissue in animals growing from 50 to $600 \mathrm{~g}$. Lipoprotein lipase activities were studied only in adipose tissue when animals grew from 50 to $400 \mathrm{~g}$.

Acetyl-CoA-carboxylase

In the liver: When the diet contained 4 or 12 p. 100 lipids, specific and total ACC activities quickly increased in the 50 to $200 \mathrm{~g}$ interval, but between 200 and $600 \mathrm{~g}$ specific activity decreased about 25 p. 100 , while total activity continued to augment slowly.

When the diet contained 21 p. 100 lipids, specific and total activities did not increase between 50 and $400 \mathrm{~g}$, but rose markedly between 400 and $600 \mathrm{~g}$.

In adipose tissues: No matter what percentage of dietary lipid was given, specific and total activities showed a marked peak at about $150 \mathrm{~g}$. They decreased rapidly at $200 \mathrm{~g}$ and became very low when the subjects reached $400 \mathrm{~g}$.

In the liver as in adipose tissues, ACC activities were higher in diets containing less lipid. On the basis of ACC activity, liver lipogenic capacity would be higher than that of the whole of the adipose tissues, at all stages, but especially in the adult animal.

\section{Lipoprotein lipase}

In the two adipose tissues studied, specific LPL activity showed a peak no matter what amount of lipid was incorporated in the ration. This peak occurred of the $150 \mathrm{~g}$ stage or a little before with the lipid-rich diets $(12$ or 21 p. 100). The foot of this peak was sifuated at the $100 \mathrm{~g}$ stage with a low-lipid diet (4 p. 100) or after weaning if the diet contained a great deal (12 or 21 p. 100). The peak was higher when the dief contained the highest proportion of lipids (21 p. 100). After this maximum, LPL specific activity decreased cons- 
tantly ; at $400 \mathrm{~g}$ it reached a rather low value, practically independent of the amount of lipid in the diet.

Total LPL activity increased between 50 and $200 \mathrm{~g}$ in both tissues studied ; it increased quicker when the diet contained more lipids. After $200 \mathrm{~g}$, it continued to augment in perirenal adipose tissue, but reached a plateau in subcutaneous dorsal adipose tissue. After $200 \mathrm{~g}$, the differences due to dietary lipid content tended to decrease, and most of those recorded at $400 \mathrm{~g}$ were non-significant.

\section{Introduction.}

La croissance des tissus adipeux est fonction de la quantité d'énergie que ces derniers sont amenés à stocker sous forme de triglycérides; ce stockage que l'on désigne habituellement et peut-être abusivement sous le vocable de lipogenèse est le résultat de deux processus différents, qui peuvent intervenir conjointement :

1) La synthèse d'acides gras à partir d'éléments non lipidiques par les tissus adipeux eux-mêmes; nous appellerons ce type de synthèse "lipogenèse de novo ».

2) Le captage d'acides gras circulants sous forme de chylomicrons ou de VLDL, provenant soit directement de l'alimentation, soit de la lipogenèse de novo effectuée par le foie.

Ces deux processus sont sous le contrôle d'enzymes clés, parmi lesquelles figurent l'acétyl CoA Carboxylase (ACC) pour le premier et la lipoprotéine lipase (LPL) pour le second.

L'acétyl CoA carboxylase (ACC, EC. 6.4.1.2) qui catalyse la carboxylation de l'acétyl CoA en malonyl CoA a été mise en évidence dès 1958 par Wakil et al. (Wakil, 1958 ; Wakil et al., 1958). Les différentes étapes de la réaction catalysée par l'enzyme ont été largement étudiées (Waite et Wakil, 1963 ; Numa et al., 1964 ; Matsuhashi et al., $1964 a$ ef $b$ ).

L'acétyl CoA carboxylase a été partiellement purifiée à partir du foie de Rat (Inove et Lowenstein, 1972 ; Matsuhashi ef al., 1964b; Nakanishi ef Numa, 1970) ou de Poulet (Gregolin et al., 1966 ; Waite et Wakil, 1963) ou à partir du tissu adipeux de Rat (Martin et Vagelos, 1962 ; Vagelos et al., 1963). Chez cette dernière $\epsilon$ spèce en particulier, la quantité d'enzyme du foie et des tissus adipeux $\in$ st, à moyen terme, contrôlée par les facteurs alimentaires.

Les travaux réalisés sur cette question ont porté sur les effets du jeône et de la réalimentation (Allman et al., 1965 ; Numa et al., 1961, 1970), sur l'influence de la fréquence des repas (Chakrabarty et Leveille, 1968, 1969), celle de l'heure du repas protéique (Peret et al., 1976a) et celle du taux protéique de la ration (Peret ef al., 1976b), sur la comparaison entre apport énergétique à base de glucides ou de lipides (Allred et Roehrig, 1973 ; Bortz ef al., 1963 ; Dakshinamurti et Desjardins, 1968, 1969) et enfin sur l'influence de la nature des lipides (Gibson et al., 1972 ; Muto et Gibson, 1970).

Les effets du taux de lipides du régime sur l'activité de l'ACC du foie et du tissu adipeux n'ont cependant pas été systématiquement recherchés.

Par ailleurs, si Lockwood et al. (1970) ont décrit l'évolution de l'activité de l'ACC du foie de Rat au cours du développement de l'animal, il n'existe, chez cette espèce, 
aucune donnée concernant son évolution dans les tissus adipeux, alors que ce travail a été réalisé chez le Porc par Anderson et Kauffman (1973).

De nombreux travaux ont montré que l'activité de la lipoprotéine lipase (LPL : EC. 3.1.1.34), et particulièrement celle des tissus adipeux, est sous le contrôle des facteurs alimentaires. Les plus anciens de ces travaux ont été passés en revue par Robinson (1970) ; depuis cette époque, de nouvelles investigations touchant ce sujet ont porté sur l'effet du jeûne (Fruchart ef al., 1972 ; Borensztajn ef al., 1972 ; Rault ef al., 1974 ; Husbands, 1972 ; Shotz et Garfinkel, 1972), la comparaison entre apport énergétique à base de glucides ou de lipides (Nillson-Ehle et al., 1975 ; Weisenburg Delorme et Harris, 1975), la nature de l'apport lipidique (Bagdade et al., 1970), la nature de l'apport glucidique (Vrana ef al., 1974), l'effet de la température ambiante (Radomski et Orme, 1971).

Toutefois le problème pratique de l'influence du taux de lipides de la ration n'a jamais été abordé.

Par ailleurs, si quelques données évoquent l'activité LPL dans les tissus adipeux à des âges différents chez l'homme et l'animal (Chlouverakis, 1962 ; Nestel et al., 1969; Husbands, 1972 ; Fruchart et al., 1973 ; Rault et al., 1974), les stades physiologiques envisagés restent le plus souvent mal définis et très limités en nombre, cependant que la composition des régimes, la consommation alimentaire et éventuellement la vitesse de croissance sont généralement passées sous silence.

Le but du présent travail est d'apporter des éclaircissements concernant la croissance de deux tissus adipeux parmi les plus importants, à savoir le sous-cutané dorsal ef le périrénal, en même temps que certains aspects de la lipogenèse chez des rats mâles auxquels sont distribués des régimes alimentaires semi-synthétiques précisément décrits, renfermant différents taux de lipides.

L'étude de la lipogenèse est abordée par le biais des mesures de l'évolution de l'activité de 1) l'acétyl CoA carboxylase dans le foie ef les deux tissus adipeux considérés, 2) la lipoprotéine lipase, uniquement dans les tissus adipeux.

\section{Matériel et méthodes.}

\section{Matériel animal.}

Des rats mâles Wistar, élevés à 8 par portée, âgés de 21 jours et pesant $50 \mathrm{~g} \pm 4 \mathrm{~g}$, sont répartis en lots de 10 animaux. Un lot est sacrifié à ce stade, n'ayant reçu pour tout aliment que le lait maternel. Les autres lots sont répartis en trois séries :

- Les animaux de la première série reçoivent un régime contenant, par rapport à la matière sèche, 4 p. 100 de lipides : ce régime est appelé " bas lipidique " (BL); - Les animaux de la deuxième série reçoivent un régime contenant 12 p. 100 de lipides : ce régime est appelé « moyen lipidique » $(\mathrm{ML})$;

- Les animaux de la troisième série reçoivent un régime contenant 21 p. 100 de lipides : ce régime est appelé « haut lipidique » $(\mathrm{HL})$.

Ces trois régimes contiennent 16 p. 100 de protéines, apportées par de la farine de hareng de Norvège. Cette farine apporte également des lipides, soit 3 p. 100 du régime ; cet apport lipidique est complété soit par de l'huile de tournesol (régime $B L$ ), 
soit par de l'huile d'arachide (régimes $\mathrm{ML}$ ef $\mathrm{HL}$ ). Le fait de compléter le contenu lipidique du régime $B L$ par de l'huile de tournesol est dicté par le souci de satisfaire largement le besoin des animaux en acide linoléique (C18:2 26$)$. La composition des trois régimes est portée sur le tableau 1.

TABLEAU 1

Composition des régimes alimentaires ( $\mathrm{g}$ de matières premières par $\mathrm{kg}$ )

\begin{tabular}{|c|c|c|c|}
\hline Régimes & $B L$ & ML & $\mathrm{HL}$ \\
\hline Taux de lipides & 4 p. 100 & 12 p. 100 & 21 p. 100 \\
\hline 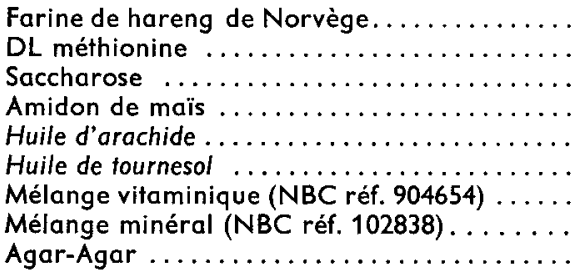 & $\begin{array}{l}220 \\
1,6 \\
236 \\
473,2 \\
-9,2 \\
10 \\
30 \\
20\end{array}$ & $\begin{array}{l}220 \\
1,6 \\
210 \\
416,4 \\
\frac{92}{10} \\
30 \\
20\end{array}$ & $\begin{array}{l}220 \\
1,6 \\
178 \\
356,4 \\
184 \\
\frac{1}{10} \\
30 \\
20\end{array}$ \\
\hline Total $\ldots \ldots \ldots \ldots \ldots \ldots \ldots \ldots \ldots \ldots$ & 1000 & 1000 & 1000 \\
\hline Matière sèche (p. 100) ..... & 93,5 & 94 & 94,5 \\
\hline Cal./g de matière sèche $\ldots \ldots \ldots \ldots \ldots \ldots$ & 3,8 & 4,2 & 4,6 \\
\hline
\end{tabular}

Pour chaque série, la consommation alimentaire et la vitesse de croissance des animaux sont mesurés quotidiennement de $50 \mathrm{~g}$ à $400 \mathrm{~g}$, puis par périodes régulières de 7 jours sur 28 au-delà de ce poids. Les rats sont élevés, après sevrage, dans une pièce éclairée de $11 \mathrm{~h}$ à $23 \mathrm{~h}$; ils sont sacrifiés entre $9 \mathrm{~h}$ et $10 \mathrm{~h}$ le matin, en fin de période sombre, c'est-à-dire pendant la digestion. Dans chaque série, les lots sont sacrifiés par décapitation successivement aux poids de $100 \mathrm{~g}, 150 \mathrm{~g}, 200 \mathrm{~g}, 400 \mathrm{~g}$ et $600 \mathrm{~g}$. Le foie ef les tissus adipeux sous-cutané dorsal et périrénal sont disséqués dans leur intégralité, rincés au sérum physiologique, essuyés et pesés. Les échantillons non traités immédiatement sont conservés à $-80^{\circ} \mathrm{C}$.

\section{Méthodes analytiques.}

a. Acétyl CoA Carboxylase. L'activité de l'ACC est mesurée dans l'intervalle 50$600 \mathrm{~g}$ dans le foie et dans les tissus adipeux périrénal et sous-cutané dorsal selon la méthode de Chang ef al. (1967), modifiée par Chakrabarty et Leveille (1968, 1969). La technique mise en œuvre comporte les étapes suivantes :

- Broyage des échantillons (500 mg à $1 \mathrm{~g}$ ) au broyeur de Thomas (foie et tissu périrénal) ou à l'Ultra-Turrax (tissu sous-cutané dorsal), dans du tampon Tris KCl-EDTA (pH 7,5 à $\left.25^{\circ} \mathrm{C}\right)$; 
- Centrifugation des homogénats à $5000 \mathrm{~g}$ puis à $50000 \mathrm{~g}$ pour l'obtention d'un surnageant limpide ;

- Préincubation du surnageant pendant $30 \mathrm{mn}$ à $37^{\circ} \mathrm{C}$ en présence de citrate de potassium ;

- Carboxylation de l'acétyl CoA par du $\mathrm{CO}_{3} \mathrm{HNa}-{ }^{14} \mathrm{C}(0,2 \mu \mathrm{C} / \mu \mathrm{M})$ pendant $2 \mathrm{mn}$ à $37^{\circ} \mathrm{C}(\mathrm{pH} 7,2)$ en présence de surnageant, de cofacteurs (citrate de $\mathrm{K}, \mathrm{ATP}$, glutathion - $\mathrm{SH}, \mathrm{Mg}^{++}$dans le cas du foie, $\mathrm{Mg}^{++}+\mathrm{Mn}^{++}$dans le cas des tissus adipeux) et de sérum albumine ;

- Arrêt de la réaction par $\mathrm{HCl} 3 \mathrm{~N}$, extraction et comptage par scintillation en milieu liquide de la radioactivité du malonyl CoA- ${ }^{14} \mathrm{C}$ formé.

Les modifications apportées par Chakrabarty et Leveille $(1968,1969)$ à la technique de Chang et al. (1967) portent sur la suppression du passage sur Sephadex du surnageant avant dosage et sur l'utilisation du manganèse dans le milieu, pour la mesure de l'activité de l'ACC des tissus adipeux.

b. Lipoprotéine-lipase. L'activité LPL n'est mesurée que dans les tissus adipeux ef seulement dans l'intervalle $50 \mathrm{~g}-400 \mathrm{~g}$. On utilise si possible des échantillons de $1 \mathrm{~g}$ à $2 \mathrm{~g}$; lorsque l'échantillon dont on peut disposer pèse moins de $500 \mathrm{mg}$, on lui adjoint, préalablement à l'extraction acétono-éthérée, $100 \mathrm{mg}$ d'albumine bovine. La méthode mise en œuvre pour la détermination de cette activité comporte les opérations suivantes:

- Obtention d'un extrait sec et dégraissé par homogénéisation dans l'acétone, puis dans l'éther ;

- Extraction de l'enzyme dans un tampon ammonium 0,025 $\mathrm{M}$ à $\mathrm{pH} 8,5$ hépariné ;

- Incubation à $37{ }^{\circ} \mathrm{C}$ de l'enzyme libérée, en présence d'un substrat triglycéridique (lipiphysan : Laboratoire Egic) activé par du plasma de Porc ;

- Extraction des acides gras libérés dans le milieu d'incubation ;

- dosage de ces acides gras.

Les quatre premières opérations sont effectuées suivant la méthode de Fruchart (1972), à cette différence près que le lipiphysan est activé par du plasma de porc à jê̂n, au lieu de plasma humain. La cinquième est effectuée par titrimétrie suivant la méthode de Dole et Meinertz (1960) en utilisant le «bleu de Nil » comme indicateur coloré.

\section{Résultats.}

Expression des résultats. - Les évolutions des diverses caractéristiques étudiées (poids frais des tissus adipeux et du foie, activités spécifiques et totales, etc...) sont exprimées en fonction du poids des animaux. - Les activités de l'acétyl,CoA carboxy. lase sont exprimées en $\mathrm{nM}$ de malonyl CoA formé par minute. - Les activités de la lipoprotéine lipase sont exprimées en $\mu$ eq d'acides gras libérés par heure dans le milieu d'incubation. - Les résultats sont accompagnés de l'erreur standard de la moyenne (SEM). - Les comparaisons statistiques sonf effectuées par analyse de variance (test $F$ ). 


\section{Consommation alimentaire (tabl. 2).}

La consommation alimentaire quotidienne moyenne des animaux de chacune des trois séries dans les intervalles $50 \mathrm{~g}-100 \mathrm{~g}, 100 \mathrm{~g}-200 \mathrm{~g}, 200 \mathrm{~g}-400 \mathrm{~g}$ et autour du poids de $500 \mathrm{~g}$ est portée sur le tableau 2 . On observe une diminution de l'appétit lorsqu'augmente le taux de lipides de la ration; cependant, de $50 \mathrm{~g}$ à $200 \mathrm{~g}$, cette diminution ne compense pas les différences de teneur énergétique entre les trois régimes, de sorte que l'apport calorique s'avère plus élevé chez les animaux $\mathrm{ML}$ et $\mathrm{HL}$ que chez les animaux BL; toutefois, le phénomène de compensation s'accentue progressivement jusqu'à conduire, au-delà de $200 \mathrm{~g}$, à une égalisation de la consommation énergétique entre les trois séries d'animaux.

\section{TABLEAU 2}

Consommotion alimentaire et vitesse de croissance chez le rat mâle en fonction du toux de lipides du régime

\begin{tabular}{cccc}
\hline Régime & BL & ML & HL \\
\hline Taux de lipides & 4 p. 100 & 12 p. 100 & 21 p. 100 \\
\hline
\end{tabular}

Consommation alimentaire moyenne

\begin{tabular}{|c|c|c|c|}
\hline 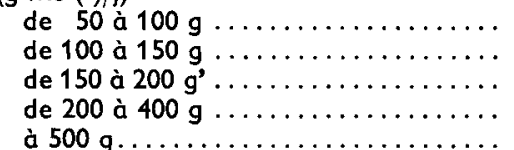 & $\begin{array}{l}10,5 \\
15,4 \\
18,5 \\
20,9 \\
22,5\end{array}$ & $\begin{array}{l}10,2(-3 \text { p. } 100)\left({ }^{2}\right) \\
14,6(-5 \text { p. } 100) \\
17,8(-4 \text { p. } 100) \\
19,5(-7 \text { p. } 100) \\
20(-11 \text { p. } 100)\end{array}$ & $\begin{array}{r}9,6(-9 \text { p. } 100) \\
13,9(-10 \text { p. } 100) \\
15,7(-15 \text { p. } 100) \\
17,0(-19 \text { p. } 100) \\
17,5(-22 \text { p. } 100)\end{array}$ \\
\hline
\end{tabular}

Age des animaux (jours)

\begin{tabular}{|c|c|c|c|}
\hline 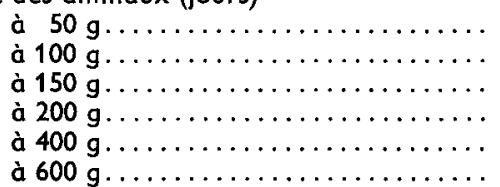 & $\begin{array}{r}21 \\
32 \\
40 \\
47 \\
81 \\
191\end{array}$ & $\begin{array}{r}21 \\
33 \\
40 \\
47 \\
85 \\
268\end{array}$ & $\begin{array}{r}21 \\
32 \\
40 \\
49 \\
91 \\
260\end{array}$ \\
\hline
\end{tabular}

(1) MS : matière sèche.

( ${ }^{2}$ Les chiffres entre parenthèses indiquent la différence de consommation alimentaire avec les animaux $B L$.

Dans ces conditions, il faut remarquer que le taux protéique des trois régimes étant identique, les animaux consomment d'autant moins de protéines que le régime qu'ils reçoivent est plus énergétique.

\section{Vitesse de croissance (tabl. 2).}

L'âge des animaux aux différents stades étudiés est porté sur le tableau 2. Entre $50 \mathrm{~g}$ et $100 \mathrm{~g}$, les animaux des trois séries présentent une vitesse de croissance iden- 
tique ; il en va de même entre $100 \mathrm{~g}$ et $200 \mathrm{~g}$ pour les rats $\mathrm{BL}$ et $\mathrm{ML}$, alors que les animaux HL commencent d'accuser un certain retard. Après $200 \mathrm{~g}$, la vitesse de croissance des lots de la série BL l'emporte sur celle des deux autres séries ; cette supériorité ne fait que s'accentuer avec le temps, au point que les animaux ML et HL atteignent le poids de $600 \mathrm{~g}$ plus de deux mois après les animaux BL.

\section{Croissance du foie et des tissus adipeux (tabl. 3).}

Foie. Quel que soit le régime utilisé, le poids du foie augmente dans tout l'intervalle étudié ; il est multiplié par $9,7,8,0$ ou 7,7 suivant que le régime renferme 4,12 ou 21 p. 100 de lipides.

\section{TABLEAU 3}

Evolution du poids frais du foie, et des tissus adipeux périrénal et sous-cufané dorsal en fonction du taux de lipides de la ration

\begin{tabular}{|c|c|c|c|c|}
\hline & \multirow{2}{*}{$\begin{array}{c}\text { Poids } \\
\text { des animaux } \\
(\mathrm{g})\end{array}$} & \multicolumn{3}{|c|}{ Régime alimentaire } \\
\hline & & $\begin{array}{c}\text { BL } \\
4 \text { p. } 100 \text { de lipides } \\
(\mathrm{mg})\end{array}$ & $\begin{array}{c}\mathrm{ML} \\
12 \mathrm{p} .100 \mathrm{de} \text { lipides } \\
(\mathrm{mg})\end{array}$ & $\begin{array}{c}\mathrm{HL} \\
21 \text { p. } 100 \text { de lipides } \\
(\mathrm{mg})\end{array}$ \\
\hline Foie & $\begin{array}{r}50 \\
100 \\
150 \\
200 \\
400 \\
600\end{array}$ & $\begin{array}{r}2180 \pm 54 * \\
5060 \pm 150 \\
6930 \pm 160 \\
10330 \pm 200 \\
15700 \pm 220 \\
21090 \pm 180\end{array}$ & $\begin{array}{r}2180 \pm 54 \\
5260 \pm 100 \\
7190 \pm 200 \\
9630 \pm 160 \\
14460 \pm 150 \\
17410 \pm 140\end{array}$ & $\begin{array}{r}2180 \pm 54 \\
4670 \pm 160 \\
6990 \pm 120 \\
8340 \pm 260 \\
13450 \pm 270 \\
16790 \pm 620\end{array}$ \\
\hline $\begin{array}{l}\text { Tissu adipeux } \\
\text { périrénal }\end{array}$ & $\begin{array}{r}50 \\
100 \\
150 \\
200 \\
400 \\
600\end{array}$ & $\begin{array}{c}170 \pm 6 \\
330 \pm 25 \\
670 \pm 45 \\
1370 \pm 72 \\
7703 \pm 544 \\
24500 \pm 1890\end{array}$ & $\begin{array}{c}170 \pm 6 \\
400 \pm 39 \\
870 \pm 61 \\
1870 \pm 180 \\
9300 \pm 682 \\
29800 \pm 1840\end{array}$ & $\begin{array}{c}170 \pm 6 \\
430 \pm 34 \\
920 \pm 64 \\
1900 \pm 163 \\
9140 \pm 640 \\
28800 \pm 3100\end{array}$ \\
\hline $\begin{array}{l}\text { Tissu adipeux } \\
\text { sous-cutané }\end{array}$ & $\begin{array}{r}50 \\
100 \\
150 \\
200 \\
400 \\
600\end{array}$ & $\begin{array}{c}800 \pm 39 \\
1560 \pm 117 \\
2580 \pm 192 \\
3570 \pm 137 \\
10480 \pm 707 \\
27850 \pm 1340\end{array}$ & $\begin{array}{r}800 \pm 39 \\
2030 \pm 98 \\
3020 \pm 121 \\
4700 \pm 152 \\
11750 \pm 875 \\
30520 \pm 992\end{array}$ & $\begin{array}{c}800 \pm 39 \\
1820 \pm 103 \\
3120 \pm 166 \\
4630 \pm 248 \\
11040 \pm 745 \\
28980 \pm 2120\end{array}$ \\
\hline
\end{tabular}

* : Erreur standard de la moyenne (SEM).

Dans les séries $\mathrm{BL}$ et $\mathrm{ML}$, l'organe présente une allométrie majorante de $50 \mathrm{~g}$ à $100 \mathrm{~g}$, une isométrie de $100 \mathrm{~g}$ à $200 \mathrm{~g}$, suivie d'une allométrie définitivement minorante. Dans la série HL, l'allométrie devient minorante dès le stade $150 \mathrm{~g}$.

Comparé à même poids d'animal, le poids de l'organe reste indépendant du régime alimentaire jusqu'au stade $150 \mathrm{~g}$. Au-delà, il est moins élevé lorsque le régime 
contient plus de lipides. A $400 \mathrm{~g}$, les écarts HL-BL, HL-ML et ML-BL atteignent respectivement 16,7 p. $100,8,5$ p. 100 et 5,7 p. 100 ; à $600 \mathrm{~g}$, ces écarts pris dans le même ordre s'élèvent à 25,6 p. 100,21 p. 100 ef 3,6 p. 100 ; ils ne sont toutefois significatifs qu'entre la série $B L$ d'une part, et les séries $H L$ et $M L$ d'autre par $(P<0,01)$.

Tissus adipeux. Les tissus adipeux sous-cutané dorsal et périrénal croissent pendant toute la période étudiée quel que soit le taux de lipides du régime. Lorsque le régime ne contient que 4 p. 100 de lipides, les deux tissus présentent l'un et l'autre une isométrie entre $50 \mathrm{~g}$ et $100 \mathrm{~g}$, suivie d'une allométrie majorante définitive. Lorsque le régime contient 12 p. 100 ou 21 p. 100 de lipides, l'allométrie devient majorante dès après le sevrage.

II faut également noter que le tissu adipeux périrénal, qui ne représente pondéralement que 20 p. 100 du tissu adipeux sous-cutané chez les animaux de $50 \mathrm{~g}$ et $100 \mathrm{~g}$, en représente 40 p. 100 à $200 \mathrm{~g}, 80$ p. 100 à $400 \mathrm{~g}$ et pratiquement 100 p. 100 à $600 \mathrm{~g}$; ceci illustre la supériorité de la capacité de croissance du tissu adipeux périrénal sur le tissu adipeux sous-cutané après le sevrage.

La distribution aux animaux des régimes $M L$ ef $H L$ provoque, par comparaison avec le régime $B L$, une augmentation sensible de la vifesse de croissance des deux tissus adipeux considérés. Mais cette augmentation n'intervient que dans l'intervalle $50 \mathrm{~g}-200 \mathrm{~g}$, entraînant une supériorité significative des séries $\mathrm{HL}$ et $\mathrm{BL}$. Au-delà de $200 \mathrm{~g}$, on observe un rattrapage de la série BL, de sorte qu'à $600 \mathrm{~g}$ les différences entre dépôts adipeux des trois séries ont pratiquement disparu en ce qui concerne le tissu adipeux sous-cutané dorsal ou ont perdu leur signification statistique en ce qui concerne le tissu adipeux périrénal.

\section{Activité de l'acétyl CoA Carboxylase.}

- Activifé spécifique (par g de tissu ou d'organe) (fig. 1).

Foie. L'évolution de l'activité spécifique (exprimée en $\mathrm{nM} / \mathrm{mn} / \mathrm{g}$ ) de l'ACC hépatique au cours du développement du Rał entre le poids vif de $50 \mathrm{~g}$ et celui de $600 \mathrm{~g}$ apparaît sur la figure $1 a$. Il ressort de ces données que :

- l'activité de l'enzyme est très faible à la fin de la période d'alimentation lactée ( $\simeq 220 \mathrm{nM} / \mathrm{mn} / \mathrm{g}$ de foie au sevrage). Elle augmente rapidement dans le cas des régimes $B L$ et $M L$ entre les stades $50 \mathrm{~g}$ et $200 \mathrm{~g}$ pour atteindre à ce dernier poids des valeurs qui s'élèvent respectivement à 1800 et $1360 \mathrm{nM} / \mathrm{mn} / \mathrm{g}$. L'activité de l'ACC décroît ensuite lentement de 20 à $30 \mathrm{p}$. 100 entre $200 \mathrm{~g}$ et $600 \mathrm{~g}$ de poids vif ;

- dans le cas du régime HL, l'activité de l'ACC reste basse tout au long de la période étudiée. Elle présente toutefois un minimum à $400 \mathrm{~g}$ avant de s'élever à nouveau entre $400 \mathrm{~g}$ et $600 \mathrm{~g}$;

- quel que soit le stade de développement considéré, l'activité spécifique de l'enzyme est d'aułant plus élevée que le taux de lipides du régime est plus bas ; au stade $200 \mathrm{~g}$, elle est inférieure de 25 p. 100 et de 88 p. 100 respectivement dans les lots $M L$ et $H L$ par rapport à sa valeur dans le lot $B L$.

Tissu sous-cutané dorsal. L'examen de la figure $1 \mathrm{~b}$ montre qu'entre $50 \mathrm{~g}$ et $600 \mathrm{~g}$, l'activité de l'ACC évolue sensiblement selon le même schéma avec les trois régimes 
alimentaires utilisés. Faible à $50 \mathrm{~g}$ (environ $6 \mathrm{nM} / \mathrm{mn} / \mathrm{g}$ ), l'activité spécifique de l'enzyme augmente très rapidement pour atteindre un maximum entre 100 et $150 \mathrm{~g}$ selon les lots. Les valeurs maximales enregistrées s'élèvent respectivement à 149,75 et $42 \mathrm{nM} / \mathrm{mn} / \mathrm{g}$ dans les lots $B L, M L$ et $H L$. Par la suite, l'activité de l'ACC décroît brus-
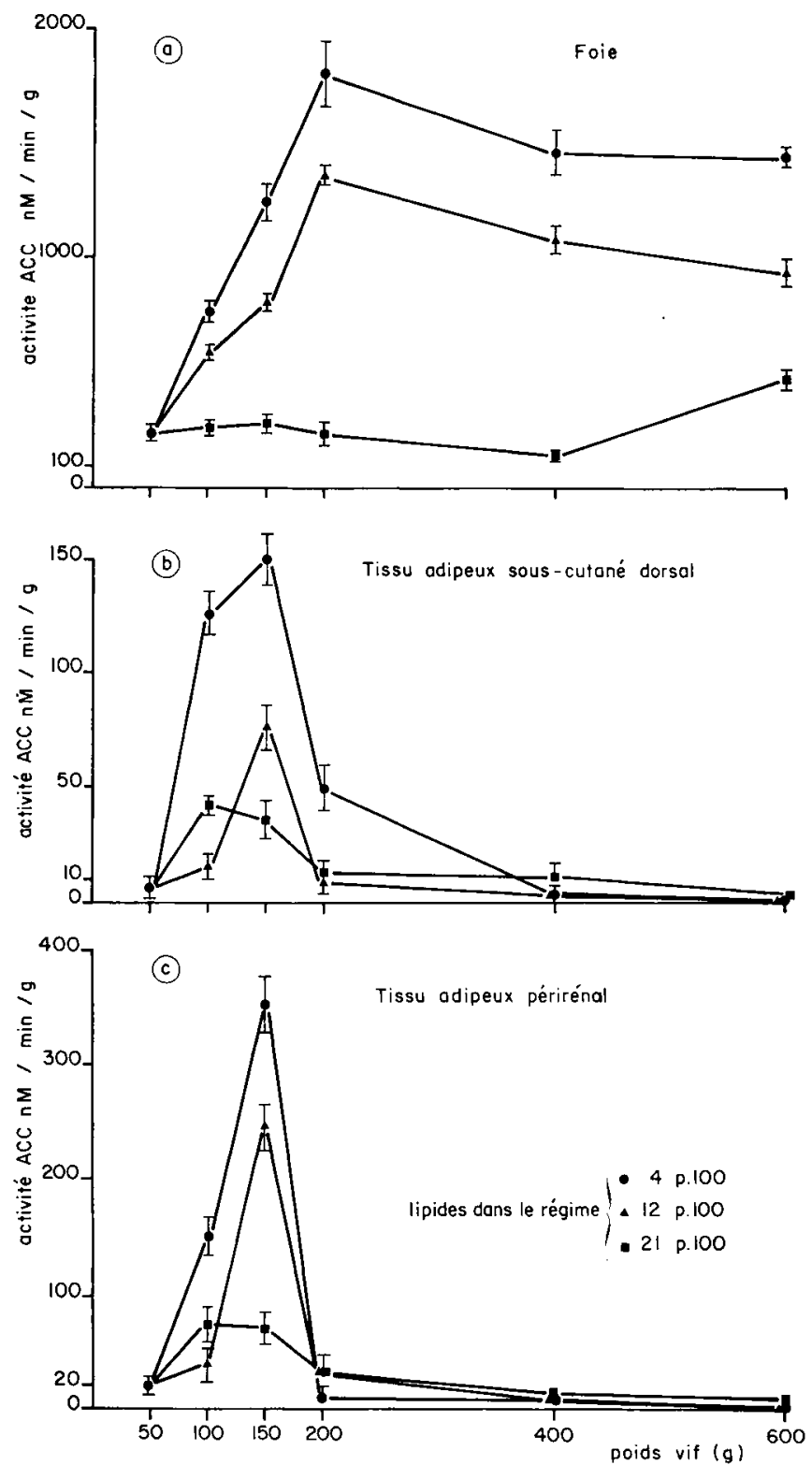

FIG. 1. - Evolution de l'activité spécifique (activité/g de tissu frais) de l'acétyl CoA carboxylase du foie et des tissus adipeux sous-cutané dorsal ef périrénal au cours du développement du rat mâle, du poids vif de $50 \mathrm{~g}$ ò celui de $600 \mathrm{~g}$. 
quement pour devenir très faible, voire non mesurable, au poids vif de $600 \mathrm{~g}$. Au moment du pic d'activité, celle-ci est d'autant plus forte que le régime renferme moins de lipides. Ensuite l'effet dépressif des lipides exogènes alimentaires est plus difficilement détectable en raison des faibles activités enregistrées.

Tissu périrénal (fig. 1c). Ce qui vient d'être dit pour le tissu sous-cutané dorsal reste valable pour le tissu périrénal. Les valeurs maximales d'activité spécifique de l'ACC sont notées entre 100 et $150 \mathrm{~g}$ de poids vif et s'élèvent respectivement à 354 , 244 et $70 \mathrm{nM} / \mathrm{mn} / \mathrm{g}$ dans les lots $B L, M L$ et $\mathrm{HL}$. II faut noter à cet égard que ces valeurs sont, dans tous les lots, supérieures à celles qui ont été mesurées dans le tissu souscutané dorsal. Par ailleurs le pic d'activité observé chez les animaux du lot BL est plus fugace que dans le tissu sous-cutané, puisqu'à $100 \mathrm{~g}$ l'activité de l'ACC n'atteint que $42 \mathrm{p}$. 100 de celle notée à $150 \mathrm{~g}$ et qu'à $200 \mathrm{~g}$ elle ne représente plus que $3 \mathrm{p} .100$ de cette dernière.

Il est important de remarquer que quels que soient le régime alimentaire ou le stade de développement considérés, l'activité spécifique de l'ACC exprimée par gramme de tissu ou d'organe est supérieure dans le foie à ce qu'elle est dans les tissus adipeux. Ainsi, même à $150 \mathrm{~g}$, stade ou l'on observe un pic dans les tissus adipeux, dans le cas du régime $B L$, l'activité spécifique de l'ACC est dans le foie respectivement 8,3 ou 3,5 fois plus forte que dans le tissu adipeux sous-cutané ou périrénal.

\section{- Activité totale (par tissu ou organe entiers) (fig. 2).}

Foie. L'évolution de l'activité totale de l'ACC hépatique est portée sur la figure $2 a$; elle augmente très rapidement entre 50 et $200 \mathrm{~g}$ dans les lots $B L$ et $M L$, passant de $500 \mathrm{nM} / \mathrm{mn} /$ foie à 18800 dans le lot $B L$ et à 13100 dans le lot $\mathrm{ML}$ contre seulement 1860 dans le lot HL. Par la suite, l'activité totale de l'enzyme continue d'augmenter, mais plus lentement : +61 p. 100 dans le lot $B L,+11$ p. 100 dans le lot $M L$ entre 200 et $600 \mathrm{~g}$ de poids vif. Dans le lot $\mathrm{HL}$, l'activité $\mathrm{ACC}$ hépatique totale, constante entre 200 ef $400 \mathrm{~g}$, augmente de 300 p. 100 entre 400 ef $600 \mathrm{~g}$. Bien que l'évolution de l'activité hépatique totale de l'enzyme soit différente selon les régimes alimentaires utilisés, cette activité est toujours d'autant plus élevée que la ration renferme moins de lipides. Ainsi, à $200 \mathrm{~g}$ elle ne représente respectivement dans les lots $\mathrm{ML}$ ef $\mathrm{HL}$ que 70 p. 100 et 10 p. 100 de sa valeur dans le lot BL alors qu'à $600 \mathrm{~g}$ de poids vif, ces pourcentages sont de 54 p. 100 et 26 p. 100.

Tissu adipeux sous-cutané dorsal. L'activité totale de l'ACC du tissu adipeux souscutané dorsal présente un pic d'activité dans les trois lots expérimentaux au poids vif de $150 \mathrm{~g}$. Entre $50 \mathrm{~g}$ et $150 \mathrm{~g}$, cette activité est multipliée respectivement par 83,43 ef 22 dans les lots BL, ML et HL (fig. $2 b$ ). Par la suite, l'activité totale de l'enzyme décroît constamment dans les lots $B L$ ef $M L$ alors que dans le lot $B L$, après un minimum de $49 \mathrm{nM} / \mathrm{mn} /$ tissu à $200 \mathrm{~g}$, elle remonte à 132 à $400 \mathrm{~g}$ pour représenter encore $84 \mathrm{nM} / \mathrm{mn} / \mathrm{tissu}$ à $600 \mathrm{~g}$, ces deux dernières valeurs étant largement supérieures à celles enregistrées aux mêmes stades de développement dans les lots BL et ML. Ainsi, à $150 \mathrm{~g}$ de poids viff, l'activité totale de l'ACC du tissu adipeux sous-cutané dorsal est d'autant plus élevée que le régime renferme moins de lipides, alors que dans les stades ultérieurs ce sont les activités enregistrées dans le lot HL (régime le plus riche en lipides) qui sont les plus fortes. 
Tissu adipeux périrénal. L'évolution de l'activité totale de l'ACC du tissu adipeux périrénal est représentée sur la figure $2 c$. Comme dans le tissu sous-cutané, on peut noter un pic au stade $150 \mathrm{~g}$. Entre $50 \mathrm{~g}$ et $150 \mathrm{~g}$ de poids vif, cette activité totale est respectivement multipliée par 112,86 et 28 dans les lots $B L, M L$ et HL. Elle décroît rapidement par la suite en présentant cependant un rebond à $400 \mathrm{~g}$ dans les lots $\mathrm{BL}$
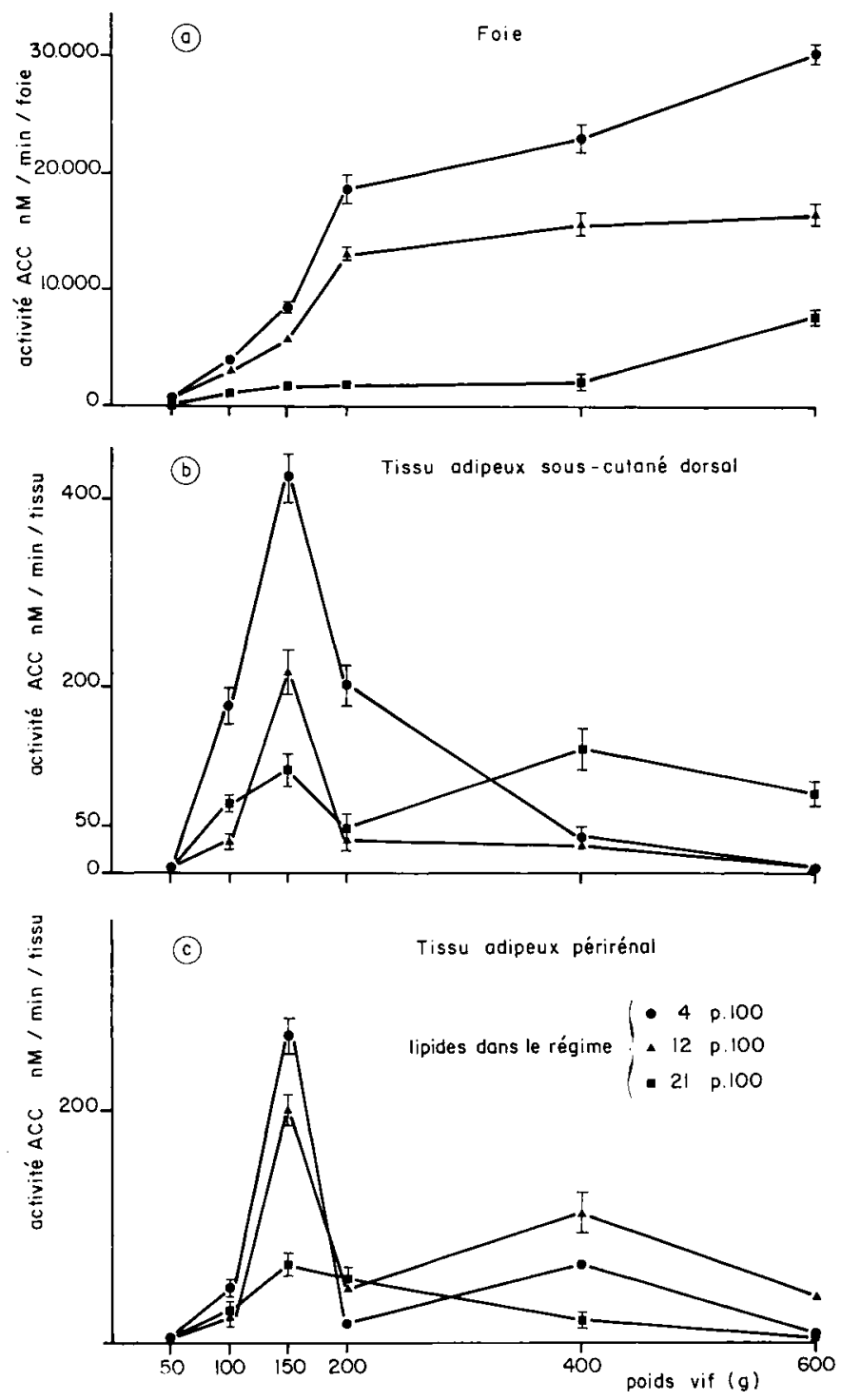

FIG. 2. - Evolution de l'activité totale (activité/tissu frais entier) de l'acétyl CoA carboxylase du foie et des tissus adipeux sous-cutané dorsal et périrénal au cours du développement du rat mâle, du poids vif de $50 \mathrm{~g}$ à celui de $600 \mathrm{~g}$. 
ef ML. Alors qu'au moment du pic, à $150 \mathrm{~g}$ de poids vif, l'activité totale de l'ACC du tissu périrénal est d'autant plus forte qu'il y a moins de lipides dans la ration, à $400 \mathrm{~g}$ l'ordre est le suivant : $M L>B L>H L$ et reste le même à $600 \mathrm{~g}$. A ce dernier stade cependant toutes les activités totales sont faibles.

Contrairement à ce que l'on a observé pour l'activité spécifique de l'enzyme, l'activité totale de l'ACC est généralement plus élevée dans le tissu sous-cutané que dans le tissu périrénal. Ceci est particulièrement net entre 100 et $200 \mathrm{~g}$ de poids vif dans le lot $B L$, chez lequel on relève les plus fortes activités. Chez les lots $B L$ et $M L$, quel que soit le stade de développement considéré, les activités totales de l'ACC sont, dans le foie, nettement plus élevées que dans les tissus adipeux. Ainsi, dans le lot BL à $150 \mathrm{~g}$, stade où l'activité des tissus adipeux est maximale, l'activité totale de l'ACC hépatique est respectivement 20 ou 33 fois plus forte que dans les tissus adipeux souscutané dorsal ou périrénal.

\section{Activité de la lipoprotéine lipase.}

- Activité spécifique (fig. 3).

Tissu sous-cutané dorsal (fig. 3a). L'examen de la figure $3 a$ montre qu'entre $50 \mathrm{~g}$ et $400 \mathrm{~g}$ l'activité spécifique (activité/g de tissu) de la lipoprotéine lipase évolue différemment suivant le taux de lipides de la ration :

- Lorsque le régime ne contient que 4 p. 100 de lipides, l'activité spécifique reste stable de $50 \mathrm{~g}$ à $100 \mathrm{~g}$, puis augmente brusquement de $40 \mathrm{p}$. 100 entre $100 \mathrm{~g}$ et $150 \mathrm{~g}$ $(\mathrm{P}<0,01)$; elle atteint un maximum à ce dernier stade, avant de revenir, à $200 \mathrm{~g}$, à son niveau initial. Cette diminution se poursuit plus progressivement entre $200 \mathrm{~g}$ ef $400 \mathrm{~g}$, intervalle au cours duquel elle diminue de moitié environ.

- Lorsque le régime contient 12 p. 100 de lipides, on note une augmentation de la LPL dès après le sevrage, avec passage par un maximum au stade $100 \mathrm{~g}$, correspondant à une augmentation de $17 \mathrm{p} .100$ entre les stades $50 \mathrm{~g}$ et $100 \mathrm{~g}$. Puis de $100 \mathrm{à} 400 \mathrm{~g}$, on observe une décroissance pratiquement linéaire de l'activité de l'enzyme. II faut remarquer cependant que les valeurs correspondant aux stades $50 \mathrm{~g}, 100 \mathrm{~g}, 150 \mathrm{~g}$ et $200 \mathrm{~g}$ ne sont pas significativement différentes entre elles et que l'on pourrait considérer que l'activité spécifique de la LPL présente un palier entre $50 \mathrm{~g}$ et $200 \mathrm{~g}$, avant de décroître de plus de la moitié entre $200 \mathrm{~g}$ et $400 \mathrm{~g}$.

- Lorsque le régime contient 21 p. 100 de lipides, on observe une augmentation très marquée de l'activité spécifique LPL dès après le sevrage atteignant 51 p. 100 entre $50 \mathrm{~g}$ et $100 \mathrm{~g}$. Aux stades $100 \mathrm{~g}$ et $150 \mathrm{~g}$, l'activité LPL est équivalente, ce qui suggère qu'elle passe par un maximum entre ces deux stades. Elle décroît ensuite linéairement de $150 \mathrm{~g}$ jusqu'à $400 \mathrm{~g}$.

Si l'on compare l'activité LPL à poids égal d'animal, on remarque qu'à $100 \mathrm{~g}$ les séries se classent dans l'ordre $H L>M L>B L$, les écarts $H L-B L$ et $H L-M L$ étant significatifs $(P<0,01 ; P<0,05)$, mais l'écart $M L-B L$ ne l'étant pas. $A 150 \mathrm{~g}$, l'ordre devient $H L>B L>M L$, mais seul l'écart $H L-M L$ est significatif $(P<0,01)$. A $200 \mathrm{~g}$, les séries se rangenf dans l'ordre $H L>M L=B L$; la différence entre les animaux $H L$ 
d'une part, $M L$ et $B L$ d'autre part est très significatif $(P<0,001)$. A $400 \mathrm{~g}$, on observe une certaine tendance au regroupement, aucun des écarts enregistrés entre les trois lots n'étant plus significatif.
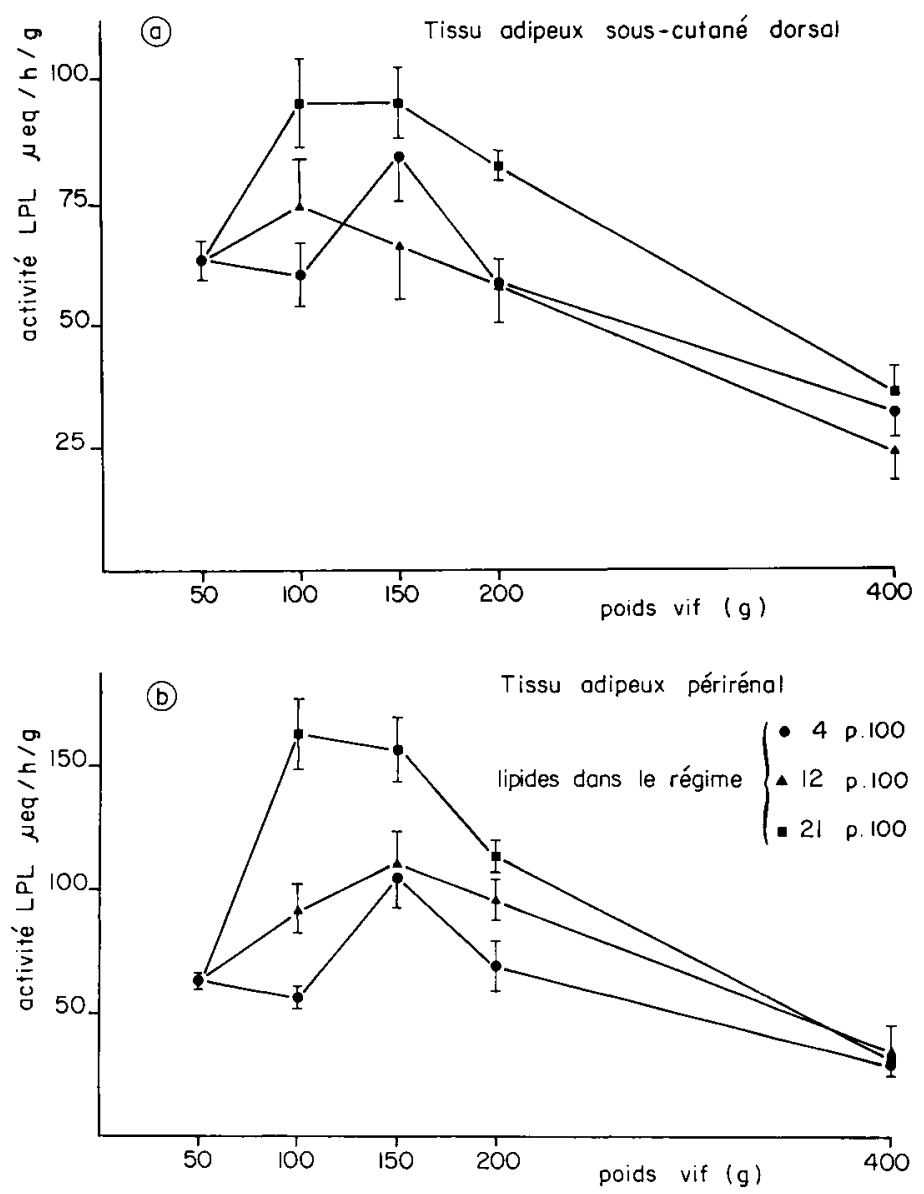

FIG. 3. - Evolution de l'activité spécifique (activité/g de tissu frais) de la lipoprotéine lipase des tissus adipeux sous-cutané dorsal et périrénal au cours du développement du rat mâle, du poids vif de $50 \mathrm{~g}$ à celui de $400 \mathrm{~g}$.

Tissu périrénal (fig. 3b). Dans l'ensemble, l'activité LPL évolue dans le tissu périrénal d'une façon assez comparable à celle que l'on observe dans le tissu sous-cutané.

- Pour le régime $B L$, l'activité LPL présente un palier entre $50 \mathrm{~g}$ et $100 \mathrm{~g}$, puis une augmentation rapide de 87 p. 100 entre $100 \mathrm{~g}$ et $150 \mathrm{~g}$, ce dernier stade correspond à un maximum, suivi d'une décroissance rapide qui ramène presque l'activité de l'enzyme à son niveau initial. Bien que d'une façon apparemment plus progressive, cette décroissance se poursuit entre $200 \mathrm{~g}$ et $400 \mathrm{~g}$, provoquant dans cet intervalle une diminution de plus de moitié de l'activité de l'enzyme. 
- Pour le régime ML, l'activité LPL croît dès après le sevrage jusqu'au stade $150 \mathrm{~g}$, où elle atteint également un maximum correspondant à un accroissement de 76 p. 100. Elle décroît ensuite linéairement, de sorte que sa valeur à $400 \mathrm{~g}$ représente à peine le tiers de sa valeur à $150 \mathrm{~g}$.

- Pour le régime $H L$, l'activité $L P L$ augmente comme dans le cas du régime $M L$, dès après le sevrage, mais d'une façon nettement plus accusée. Elle parvient à un maximum situé selon toute vraisemblance entre 100 et $150 \mathrm{~g}$ et correspondant à une augmentation d'au moins 159 p. 100, avant de décliner rapidement jusqu'à $200 \mathrm{~g}$, puis plus progressivement, semble-t-il, entre 200 et $400 \mathrm{~g}$.

La comparaison à un même poids vif d'animal indique que les trois séries se placent dans l'ordre $\mathrm{HL}>\mathrm{ML}>\mathrm{BL}$ sans interruption entre $50 \mathrm{~g}$ et $200 \mathrm{~g}$, cependant que, dans cet intervalle, les écarts entre les différents lots varient de façon considérable suivant le stade considéré. Mais à partir de $200 \mathrm{~g}$, on assiste à un regroupement général encore plus marqué que dans le tissu sous-cutané, à tel point qu'à $400 \mathrm{~g}$ les activités $L P L$ sont équivalentes dans les trois séries.

\section{- Activité totale (fig. 4).}

Tissu adipeux sous-cutané dorsal. L'évolution de l'activité totale LPL dans le tissu adipeux sous-cutané dorsal est portée sur la figure $4 a$.

- Dans le cas du régime BL, cette activité quadruple du stade $50 \mathrm{~g}$ au stade $150 \mathrm{~g}$; elle reste pratiquement stable entre $150 \mathrm{~g}$ et $200 \mathrm{~g}$, avant de reprendre un accroissement de l'ordre de 75 p. 100 lorsque le poids des animaux passe de $200 \mathrm{~g}$ à $400 \mathrm{~g}$. On peut également considérer l'évolution de la LPL totale comme un phénomène pratiquement linéaire, interrompu par un à-coup au stade $150 \mathrm{~g}$, correspondant au pic d'activité de l'activité spécifique de l'enzyme.

- Dans le cas du régime $M L$, l'activité LPL totale augmente quasi linéairement et se trouve multipliée par 6 dans l'intervalle $50 \mathrm{~g}-200 \mathrm{~g}$. A ce stade, elle atteint apparemment un plateau où elle reste située jusqu'au stade $400 \mathrm{~g}$.

- Dans le cas du régime HL, l'évolution de l'activité de l'enzyme est du même type que précédemment : son activité croît linéairement de $50 \mathrm{~g}$ à $200 \mathrm{~g}$ et elle est multipliée par 8,4 dans cet intervalle; elle semble plafonner à ce stade puisqu'elle conserve la même valeur au stade $400 \mathrm{~g}$.

A poids égal d'animal, on observe l'ordre $\mathrm{HL}>\mathrm{ML}>\mathrm{BL}$ à tous les stades étudiés, sauf à $400 \mathrm{~g}$ où les séries se placent dans l'ordre $\mathrm{HL}>\mathrm{BL}=\mathrm{ML}$. Cependant, la signification statistique des différences entre séries varie selon le stade considéré : ainsi, à $100 \mathrm{~g}$, les activités $L P L$ totales des séries $\mathrm{HL}$ et $\mathrm{ML}$ ne sont pas différentes entre elles, mais l'une ef l'autre sont significativement supérieures à celle de la série $B L$ ( $P<0,01$ et $P<0,05$ respectivement) ; à $150 \mathrm{~g}$, l'activité $L P L$ totale de la série HL est supérieure aux activités $M L$ et $B L$, qui ne sont pas différentes entre elles; ‘̀ $200 \mathrm{~g}$, les trois écarts $\mathrm{HL}-\mathrm{BL}, \mathrm{HL}-\mathrm{ML}$ ef $\mathrm{ML}-\mathrm{BL}$, qui atteignent respectivement 134 p. 100 , 41 p. 100 ef 66 p. 100 sont tous significatifs $(P<0,001 ; P<0,05 ; P<0,01)$. A $400 \mathrm{~g}$, la série $\mathrm{HL}$ reste supérieure aux séries $M L$ et $B L$, qui se sont rejointes de nouveau.

Tissu périrénal. Comme le montre la figure $4 b$, lorsque le régime ne contient que 4 p. 100 de lipides, l'activité LPL totale du tissu adipeux périrénal croît assez lentement, 
bien que significativement, de $50 \mathrm{~g}$ à $100 \mathrm{~g}$; puis, de $100 \mathrm{~g}$ à $400 \mathrm{~g}$, elle augmente en fonction du poids vif d'une manière que l'on pourrait tenir pour linéaire, si ce n'était le léger à-coup correspondant au pic d'activité spécifique de l'enzyme observé au stade $150 \mathrm{~g}$. Si l'on considère l'ensemble de l'intervalle étudié, l'activité LPL totale augmente de près de 24 fois lorsque le poids des animaux passe de $50 \mathrm{~g}$ à $400 \mathrm{~g}$.
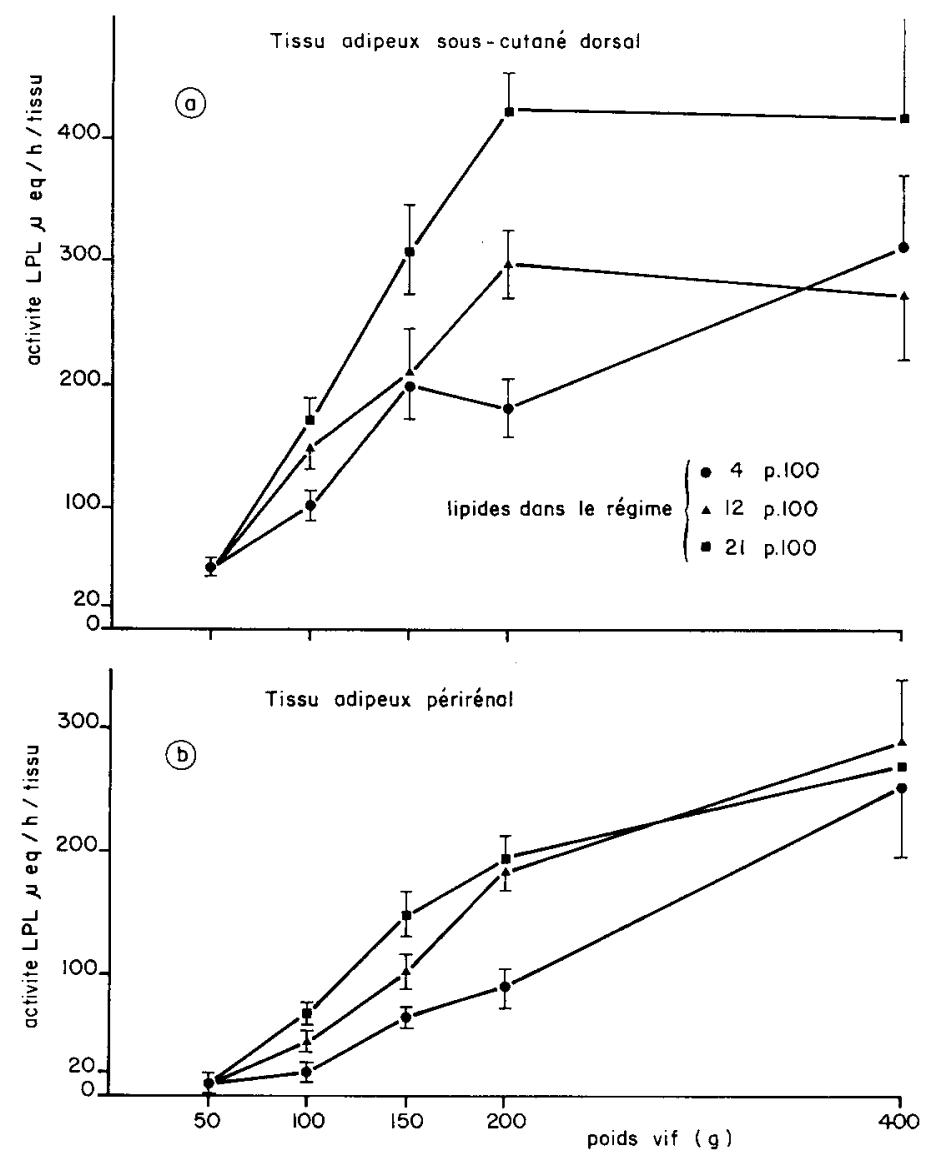

FIG. 4. - Evolution de l'activité totale (activité/tissu entier) de la lipoprotéine lipase des tissus adipeux sous-cutané dorsal et périrénal au cours du développement du rat mâle, du poids vif de $50 \mathrm{~g}$ à celui de $400 \mathrm{~g}$.

Lorsque le régime contient 12 p. 100 et 21 p. 100 de lipides, les activités LPL totales évoluent en fonction du poids vif de l'animal selon des courbes de type sigmoïde :

- dans le cas du régime $\mathrm{ML}$, on observe une phase d'autoaccélération (courbure de la courbe représentative tournée vers le haut) dans l'intervalle $50 \mathrm{~g}-200 \mathrm{~g}$ correspondant à une augmentation de 17,3 fois de l'activité LPL totale. A cette phase d'autoaccélération succède une phase d'auto-freinage (courbure de la courbe tournée vers 
le bas) qui correspond cependant dans l'intervalle $200 \mathrm{~g}-400 \mathrm{~g}$ à une augmentation de 57 p. 100 . Sur l'ensemble de l'intervalle $50 \mathrm{~g}-400 \mathrm{~g}$, l'activité de l'enzyme pour la totalité du tissu est multipliée environ par 27.

- pour le régime $H L$, la phase d'autoaccélération se limite à l'intervalle $50 \mathrm{~g}-150 \mathrm{~g}$, dans lequel l'activité LPL totale est multipliée par 14. Dans la phase d'autofreinage qui lui succède, l'augmentation de l'activité de l'enzyme pour le tissu entier est encore de 82 p. 100. Dans l'intervalle $50 \mathrm{~g}-400 \mathrm{~g}$, l'activité LPL pour l'ensemble du tissu périrénal est multipliée par 25,5 .

La comparaison entre les trois régimes à poids égal d'animal indique en premier lieu que les lots se rangent dans l'ordre HL $>M L>B L$ jusqu'au stade $150 \mathrm{~g}$, tous les écarts étant significatifs ; mais à $200 \mathrm{~g}$, la série $M L$ rejoint la série $H L$, de sorte qu'à ce siade les lots se placent dans l'ordre $H L=M L>B L(P<0,001)$. A $400 \mathrm{~g}$, les trois séries se sont regroupées et aucune différence n'est significative.

En résumé, lorsque le régime contient 4 p. 100 de lipides, on note dans les deux tissus adipeux une progression continue de l'activité de l'enzyme avec toutefois un à-coup plus ou moins marqué entre $100 \mathrm{~g}$ et $200 \mathrm{~g}$, conséquence du pic d'activité spécifique observé entre $100 \mathrm{~g}$ et $150 \mathrm{~g}$.

Lorsque le régime contient 12 p. 100 et 21 p. 100 de lipides, on relève une évolution différente caractérisée par une forte poussée de l'activité LPL totale depuis le sevrage jusqu'à $200 \mathrm{~g}$, suivie soit d'un ralentissement de sa progression dans le cas du tissu adipeux sous-cutané dorsal, soit d'une stabilisation dans le cas du tissu adipeux périrénal.

Finalement, après une période allant approximativement du sevrage à la puberté, durant laquelle les activités enzymatiques divergent suivant le taux de lipides du régime, on observe une convergence de ces activités, ou du moins une évolution parallèle, lorsque les animaux atteignent l'éłat de maturité.

La comparaison des activités LPL totales dans le tissu adipeux sous-cutané et le tissu adipeux périrénal montre que celle du premier, à peu près 5 fois plus élevée que celle du second au sevrage, ne lui est pratiquement plus supérieure au stade $400 \mathrm{~g}$ Il y a donc, comme en ce qui concerne le poids frais, un rattrapage quasi total du souscutané par le périrénal. Ce rattrapage s'amorce plus tôt lorsque le régime alimentaire est riche en lipides.

\section{Discussion.}

Consommation alimentaire, croissance globale, croissance du foie et des tissus adipeux. Dans le présent travail, des lots de rats reçoivent, dans l'intervalle $50 \mathrm{~g}-600 \mathrm{~g}$, des régimes alimentaires contenant un même taux de protéines, soit 16 p. 100, mais des taux différents de lipides, soit 4 p. 100,12 p. 100 ou 21 p. 100 respectivement. Les animaux sont comparés aux poids de $100 \mathrm{~g}, 150 \mathrm{~g}, 200 \mathrm{~g}, 400 \mathrm{~g}$ et $600 \mathrm{~g}$.

Les résultats montrent que l'augmentation du taux de lipides de la ration, c'est-àdire l'augmentation de leur richesse énergétique, entraîne une diminution progressive de l'appétit; cela conduit après le stade $200 \mathrm{~g}$, qui correspond approximativement à l'acquisition de la maturité sexuelle, à une égalisation de l'ingestion énergétique entre les différents lots. A cette diminution de la consommation alimentaire correspond 
une moindre ingestion de protéines, qui peut expliquer en partie la réduction de la vitesse de croissance des animaux qui reçoivent les régimes les plus énergétiques.

Dans l'intervalle $50 \mathrm{~g}-150 \mathrm{~g}$, le poids du foie est indépendant de la composition de la ration ; passé ce stade, il est moins élevé chez les animaux « moyen lipidique » et "haut lipidique » que chez les animaux «bas lipidique»: ce phénomène est également à rapprocher du fait que ces animaux tendent à consommer sensiblement moins de protéines.

Dans l'intervalle $50 \mathrm{~g}-200 \mathrm{~g}$, la croissance des tissus adipeux sous-cutané dorsal et périrénal est stimulée par l'enrichissement du régime en lipides; cependant, la supériorité acquise de ce fait à la puberté s'atténue peu à peu et tend à disparaître lorsque les animaux sont parvenus à complète maturité : ceci est à mettre en regard avec l'alignement de la consommation énergétique qui s'instaure progressivement après $200 \mathrm{~g}$.

Activité de l'Acétyl CoA Carboxylase. L'évolution de l'activité spécifique de l'ACC hépatique que nous avons enregistrée chez les animaux des lots $B L$ et $M L$ est en tout point identique à celle décrite par Lockwood et al. (1970). En effet, ces auteurs ont noté un pic d'activité spécifique entre 40 et 50 jours d'âge alors que nous observons une activité maximale chez les rats de $200 \mathrm{~g}$ de poids vif, qui sont âgés de 47 jours. En accord avec Lockwood et al. (1970) et avec Taylor ef al. (1967), la faible activité lipogénique hépatique du rat avant sevrage nous semble résulter de la forte teneur en lipides du lait de la mère, ces lipides exogènes alimentaires ayant une action rétro-inhibitrice sur la lipogenèse de novo. Lockwood et al. (1970) ont d'ailleurs apporté la preuve d'un tel phénomène en observant, dès le sevrage précoce du rat à 14 jours avec un régime hypolipodique, un accroissement important et quasi immédiat de l'activité des enzymes impliquées dans la lipogenèse de novo.

L'activité hépatique totale de l'ACC qui s'accroît très rapidement entre 50 et $200 \mathrm{~g}$ n'augmente plus que faiblement dans les lots BL et ML entre 200 et $600 \mathrm{~g}$.

L'administration d'un régime hyperlipidique supprime toute variation significative des activités spécifique ou totale de l'enzyme entre 100 et $400 \mathrm{~g}$. On observe cependant, entre 400 et $600 \mathrm{~g}$, une augmentation de ces activités, augmentation difficilement explicable dans l'état actuel de nos connaissances.

L'ingestion de lipides exogènes alimentaires provoque, à tous les stades de développement considérés, une réduction d'activité de l'ACC hépatique, confirmant par la même l'effet rétro-inhibiteur des graisses du régime sur la lipogenèse de novo.

Si aucune étude systématique n'a été effectuée au niveau des tissus adipeux du Rat, quelques travaux permettent cependant de penser que, comme nous l'avons observé, l'intensité de la lipogenèse dans ces tissus décroît avec l'âge. Ainsi, Benjamin et al. (1961) et Gellhorn et Benjamin (1965) trouvent une incorporation d'acétate ${ }^{14} \mathrm{C}$ dans les acides gras du tissu adipeux 7 fois plus importante chez le Rat de 100 à $150 \mathrm{~g}$ que chez le Rat de 250 à $430 \mathrm{~g}$. Des travaux plus récents de Holm et al. (1975) ont montré, chez le Rat, que des adipocytes isolés de même taille synthétisent d'autant moins de lipides qu'ils sont issus d'animaux plus âgés.

Des études plus systématiques ont été conduites chez le Porc par Allee (1970) et par Anderson et Kauffman (1973). D'après Allee, l'incorporation in vifro, de glucose U.14C dans les acides gras du tissu adipeux croît du sevrage à l'âge de 67 jours puis diminue rapidement pour atteindre à l'âge de 179 jours des valeurs environ 10 fois 
inférieures à celles notées à 67 jours. Selon Anderson et Kauffman, l'acétyl CoA carboxylase présente un pic d'activité spécifique et totale qui se situe entre l'âge de 4 mois et celui de 6 mois.

Ainsi, il semble bien que toutes les données de la littérature confirment les résultats que nous avons obtenus $€ \dagger$ qui mettent en évidence une activité lipogénique importante dans les tissus adipeux à un stade bien défini du développement de l'animal, activité qui décroît par la suite pour atteindre des valeurs très faibles chez l'animal plus âgé.

En ce qui concerne les rôles respectifs du foie ef des tissus adipeux dans la lipogenèse de novo, la situation n'est pas aussi claire. Des travaux anciens (Feller, 1954 ; Hausberger et al., 1954 ; Favarger, 1965) aboutissent à la conclusion que l'activité lipogénique des tissus adipeux est supérieure à celle du foie. Cependant, des résultats plus récents de Chakrabarty et Leveille $(1968,1969)$ et de Volpe et Marasa (1975) permettent de constater que les conclusions peuvent être fort différentes selon le mode d'expression des résultats de mesure d'activité de l'ACC. En effet, exprimée en $\mathrm{nM} / \mathrm{mn} / \mathrm{mg}$ de protéines, l'activité de l'enzyme dans les tissus adipeux peut être, selon les conditions expérimentales, du même ordre de grandeur voire même supérieure à ce qu'elle est dans le foie. Par contre, exprimée par gramme de tissu ou d'organe, l'activité hépatique est toujours beaucoup plus élevée dans le foie que dans le tissu adipeux.

Sur la base des résultats que nous avons obtenus, si l'on tente d'établir globalement la capacité lipogénique du foie d'une part, des tissus adipeux d'autre part, en adoptant pour l'activité spécifique de l'ACC dans ces tissus la moyenne des valeurs mesurées dans le périrénal et dans le sous-cutané et pour masse des tissus adipeux les données obtenues par dissection de tous les tissus adipeux blancs, l'on aboutit à l'approximation suivante :

- en dehors du stade de croissance $150 \mathrm{~g}$ où les tissus adipeux pourraient représenter 20 à 30 p. 100 de la somme «foie + tissus adipeux » de l'activité acétyl CoA carboxylasique, ces tissus ne joueraient qu'un rôle mineur inférieur à 5 p. 100 ;

- en particulier, les tissus adipeux n'auraient que peu d'importance par rapport au foie chez le Rat adulte. Cette constatation peut être comparée à celle de Jansen et al. (1967) qui ont montré que la quantité de lipides synthétisés chez la souris adulte diminue constamment avec l'âge dans les tissus adipeux et extra hépatiques alors qu'elle ne cesse d'augmenter dans le foie.

II reste cependant difficile de conclure définitivement quant aux parts respectives du foie et des tissus adipeux dans la lipogenèse de novo sur la seule base de l'activité de I'ACC qui n'est qu'une des enzymes, certes importante, intervenant dans cette voie métabolique. C'est pourquoi un nouveau travail est en cours dans notre laboratoire, travail dans lequel sera recherchée, au cours du développement, l'évolution de deux autres enzymes impliquées dans la lipogenèse de novo : l'enzyme malique et la glucose 6-P-déshydrogénase. Cette étude sera menée à la fois chez le mâle entier et castré ainsi que chez la femelle entière ou castrée ; en effet, la présence du pic d'activité de l'ACC des tissus adipeux, dans une période du développement qui prélude à l'instauration de la puberté, nous amène à nous demander si ce phénomène n'est pas lié à un changement d'équilibre hormonal. 
L'effet dépressif des lipides exogènes alimentaires sur l'activité de l'ACC se manifeste aussi bien au niveau des tissus adipeux qu'à celui du foie. Ceci confirme le fait que certaines propriétés de l'enzyme des tissus adipeux sont analogues à celles de l'enzyme hépatique (Dakshinamurti et Desjardins, 1969).

Enfin la supériorité de l'activité spécifique de l'ACC du tissu adipeux périrénal par rapport à celle du tissu adipeux sous-cutané au stade $150 \mathrm{~g}$ est en accord avec les données de Gellhorn et Benjamin (1965) selon lesquelles le taux d'incorporation d'acétate dans les acides gras est significativement plus élevé dans le tissu périrénal que dans le sous-cutané.

\section{Activité de la lipoprotéine lipase :}

Le travail le plus ancien concernant l'activité LPL spécifique $(\mu \mathrm{eq} / \mathrm{g})$ dans les tissus adipeux en fonction de l'âge est, à notre connaissance, celui de Angerval (1960) ; ce dernier observe que cette activité est plus élevée dans les tissus adipeux de poulets âgés de 6-7 mois que dans ceux de poules âgées de 2 ou 3 ans. Peu de temps après, Chlouverakis (1962) montre que l'enzyme est plus active dans le tissu épididymaire de rats âgés de 4-5 semaines que dans celui de rats âgés de plus de 5 mois. Etudiant le tissu épididymaire de rats dont le poids vif s'étage de $130 \mathrm{~g}$ à $350 \mathrm{~g}$. Nestel et al. (1969) notent également un amenuisement de l'activité LPL rapportée au nombre d'adipocytes lorsque les animaux avancent en âge. Dans le tissu adipeux sub-péritonéal de poulets mâles de 8-10 semaines, de poulettes de 16 semaines ef de poules de 36-40 semaines, Husbands (1972) relève que l'activité LPL est la plus élevée chez les poulettes et la plus faible chez les poules. Krauss et al. (1974) remarquent que l'enzyme est plus active chez les hommes jeunes que chez les hommes agés. Enfin, Fruchart ef al. (1973) dans le tissu adipeux sous-cutané dorsal, semble-t-il, et Rault ef al. (1974) dans le gras épididymaire de rats âgés de 6, 8 ef 15 semaines décèlent une décroissance rapide de l'activité LPL de 6 à 8 semaines, survie d'une décroissance très progressive de 8 à 15 semaines.

Ainsi, malgré la diversité de l'origine des tissus adipeux, et la disparité des méthodes analytiques, tous les auteurs précédents s'accordent à reconnaître une moindre activité LPL spécifique chez les sujets qui ont atteint leur pleine maturité.

Les résultats du présent travail sont en accord avec cette conclusion, mais ils ont permis en outre de décrire de façon détaillée l'évolution de l'activité spécifique de l'enzyme depuis le sevrage jusqu'à l'âge adulte et de mettre en évidence le pic d'activité qu'elle présente entre sevrage et puberté, indépendamment du taux de lipides de la ration.

Les travaux cités plus haut n'ont pas été conduits de manière assez systématique pour faire apparaître ce phénomène. Toutefois, on peut penser que Fruchart et al. (1973) et Rault et al. (1974) ont été très près d'y parvenir : en effet, ces auteurs ont observé chez le Rat mâle une décroissance rapide de l'activité de l'enzyme entre 6 ef 8 semaines, c'est-à-dire sans doute approximativement entre les stades $150 \mathrm{~g}$ et $250 \mathrm{~g}$, suivie d'un palier ou d'une décroissance lente entre 8 et 15 semaines, c'està-dire aproximativement entre les stades $250 \mathrm{~g}-450 \mathrm{~g}$ : cela laisse à penser qu'au stade $150 \mathrm{~g}$, ils se trouvaient placés au voisinage d'un pic d'activité qu'ils eussent observé s'ils avaient effectué des mesures chez des animaux d'un âge compris entre 3 et 6 semaines. 
En ce qui concerne les variations d'activité LPL en fonction du taux de lipides, la bibliographie ne fournit à notre connaissance, aucune donnée ; nos résultats montrent que l'enrichissement du régime alimentaire en lipides provoque dès après le sevrage l'augmentation de l'activité LPL spécifique et fait apparaître plus tôt le pic d'activité maximale de l'enzyme; de plus, lorsque le régime est très riche en lipides ( $>12$ p. 100), ce pic atteint un niveau supérieur.

Nos résultats indiquent également que l'activité $L P L$ totale évolue différemment dans les deux tissus adipeux sous-cutané dorsal et périrénal ; alors que dans le premier, elle semble plafonner à partir du stade $200 \mathrm{~g}$, elle continue à croître de façon notable dans le second. Ceci est à rapprocher du fait que, du point de vue pondéral, le tissu périrénal, cinq fois moins important que le tissu sous-cutané au sevrage, ne lui est inférieur que de 20 p. 100 environ au stade $400 \mathrm{~g}$, et lui est pratiquement équivalent à $600 \mathrm{~g}$.

\section{Conclusions.}

Les résultats de ce travail amènent aux conclusions essentielles suivantes :

- Les tissus adipeux manifestent, au cours du développement du Rat mâle, une activité métabolique intense dans l'intervalle 100-150 g de poids vif, c'est-à-dire entre 32 et 40 jours d'âge : à ce stade, les activités spécifiques de l'acétyl CoA carboxylase et de la lipoprotéine lipase présentent un maximum marqué, indice d'une synthèse et d'une captation maximales d'acides gras par les tissus adipeux.

- Sur la base de l'activité de l'acétyl CoA carboxylase, l'activité lipogénique du foie paraît très supérieure à celle de l'ensemble des tissus adipeux, surtout après l'acquisition de la maturité sexuelle.

- L'enrichissement en lipides du régime alimentaire, qui entraîne une réduction de la synthèse d'acides gras aussi bien dans le foie que dans les tissus adipeux, provoque, dans le même temps, une augmentation de la captation d'acides gras par ces derniers, qui se traduit par un développement plus intense des tissus adipeux entre $50 \mathrm{~g}$ et $200 \mathrm{~g}$ de poids vif.

Réunion Groupe Développement INRA/Productions animales Thiverval-Grignon, 14-15 avril 1976.

\section{Références}

ALLEE G. L., 1970. Effect of dietary protein and fat, age and periodicity of eating on performance and carcass characteristics and on lipogenesis and enzymatic activity in adipose tissue of the pig. Thesis, Urbana, Champain, Univ. of Illinois, 176 pP.

ALLMAN D. W., HUBBARD D. D., GIBSON D. M., 1965 . Fatty acid synthesis during fat-free refeeding of starved rats. J. Lipid Res., 6, 63-74.

ALLRED J. B., ROEHRIG K. L., 1973. Inhibition of rat liver acetyl coenzyme A carboxylase by $N^{6}$, $\mathrm{O}^{2}$-dibutyryl cyclic adenosine 3'-5'-monophosphate in vitro. J. biol. Chem., 248, 4131-4133.

ANDERSON D. B., KAUFFMAN G., 1973. Cellular and enzymatic change in Porcine adipose tissue during growth. J. Lipid Res., 14, 160-168. 
ANGERVAL G., 1960. Lipoprotein lipase activity in adipose tissue from chicken and adult human. Acta physiol., scand., 48, 71-77.

BAGDADE J., HOZZARD W., CARLIN J., 1970. Effect of insaturated dietary fat on plasma lipoprotein lipase activity in normal and hyperlipidemic states. Metabolism, 19, 1020-1024.

BENJAMIN W., GELLHORN A., WAGNER M., KUNDEL H., 1961. Effect of aging on lipid composition and metabolism in the adipose tissues of the rat. Am. J. Physiol., 102, 540-546.

BORENSZTAJN J., SAMOLS D., RUBENSTEIN A., 1972. Effects of insulin on lipoprotein lipase activity in the rat heart and adipose tissue. Am. J. Physiol., 223, 1271-1275.

BORTZ W., ABRAHAM S., CHAIKOFF I. L., 1963. Localization of the block in lipogenesis resulting from feeding fat. J. biol. Chem., 238, 1266-1272.

CHAKRABARTY K., LEVEILLE G. A., 1968. Influence of periodicity of eating on the activity of various enzymes in adipose fissue, liver and muscle of the rat. J. Nutr., 96, 76-82.

CHAKRABARTY K., LEVEILLE G. A., 1969. Acetyl-CoA-carboxylase and fatty acid synthetase activities in liver and adipose tissue of meal fed rats. Proc. Soc. exp. Biol. Med., 131, 1051-1054.

CHANG H. C., SEIDMAN I., TEEBOR LANE M. D., 1967. Liver acetyl-CoA-carboxylase and Fatty acid synthetase relative activities in the normal state and in hereditary obsesity. Biochem. biophys. Res. Commun., 28, 682-686.

CHLOUVERAKIS C., 1962. Adipose tissue lipoprotein lipase activity in rats of two different ages. Nature, 196, 1103.

DAKSHINAMURTI K., DESJARDINS P. R., 1968. Lipogenesis in biotin deficiency. Can. J. Biochem. 46, $1261-1267$.

DAKSHINAMURTI K., DESJARDINS P. R., 1969. Acetyl-CoA-carboxylase from rat adipose tissue. Biochem. biophys. Acta, 176, 221-229.

DOLE V., MEINERTZ H., 1960. Microdetermination of long-chain fatty acids in plasma and tissues. J. biol. Chem., 235, 2595-2599.

FAVARGER P., 1965. Relative importance of different tissues in the synthesis of fatty acids. In, REYNOLD A. E., CAHILL, G. F. Hanbook of Physiology, Adipose tissue, Sect. 5, 19-23, Amer. Physiol. Soc., Washington D. C.

FELLER D. D., 1954. Metabolism of adipose tissue. I. Incorporation of acetate carbon into lipids by slices of adipose tissue. J. biol. Chem., 206, 171-180.

FRUCHART J., 1972. Contribution à l'étude de la lipoprotéine lipase du plasma post-héparine et des tissus. Thèse Doct. Etat Pharmacie, Lille (France).

FRUCHART J., SEZILLE G., JAILLARD J., SCHERPEREEL P., DEWAILLY P., 1972. Ełude des variations, chez le Rat, en fonction de l'état nutritionnel, de l'activité lipoprotéine lipase du tissu adipeux et du myocarde. C. R. Soc. Biol., 166, 68-70.

FRUCHART J., SEZILLE G., JAILLARD J., SCHERPEREEL P., DEWAILLY P., RAULT C., 1973. Mesure de l'activité lipoprotéine lipase du tissu adipeux chez l'Homme et chez l'animal. Ann. Biol. clin., 31, 131-132.

GELLHORN A., BENJAMIN W., 1965. Effect of aging on the composition and metabolism of adipose tissue in the Rat. In REYNOLD A. E., CAHILL G. F. Jr. Handbook of Physiology, Adipose tissue. Sect. 5, 399-405, Amer. Physiol. Soc. Washington D. C.

GIBSON D. M., LYONS R. T., SCOTT D. F., MUTO Y., 1972. Synthesis and degradation of the lipogenic enzymes of rat liver. Adv. Enz. Reg., 10, 187-204.

GREGOLIN C., RYDER E., KLEINSCHMIDT A. K., WARNER R. C., LANE M. D., 1966. Molecular characteristics of liver acetyl CoA carboxylase. Proc. nat. Acad. Sci., USA, 56, 148-155.

HAUSBERGER F. X., MILSTEIN S. W., RUTMAN R. J., 1954. The influence of insuline on glucose utilization in adipose and hepatic tissues in vitro. J. biol. Chem., 208, 431-438.

HOLM G., JACOBSSON B., BJÖRNTORP P., SMITH U., 1975. Effects of age and cell size on rat adipose tissue metabolism. J. Lipid. Res., 16, 461-464.

HUSBANDS D., 1972. The distribution of LPL in tissues of the domestic fowl and the effects of feeding and starving Br. Poult. Sci., 13, 85-90.

INOUE H., LOWENSTEIN J. M., 1972. Acetyl coenzyme A carboxylase from rat liver. Purification and demonstration of different subunits. J. biol. Chem., 247, 4825-4832.

JANSEN G. R., ZANETTI M. E., HUTCHISON C. F., 1967. Studies on lipogenesis in vivo : Comparaison of cholesterol and fatty acid synthesis in rats and mice. Biochem. J., 102, 864-870. 
KRAUSS R., LEVY R., FREDRICKSON D., 1974. Selective measurement of two lipase activities in post heparine plasma from normal subjects and patients with hyperlipoproteinemia. J. clin. Invest., 54, 1107-1124.

LOCKWOOD E. A., BAILEY E., TAYLOR C. B., 1970. Factors unvolved in changes in hepatic lipogenesis during development of the rat. Biochem. J., 118, 155-162.

MARTIN D. B., VAGELOS P. R., 1962. The mechanism of tricarboxylic acid cycle regulation of fatty acid synthesis. J. biol. Chem., 237, 1787-1792.

MATSUHASHI M., MATSUHASHI S., LYNEN F., 1964a. Zur biosynthese der Fettsäuren. IV. AcetylCoA-carboxylase aus Hefe. Biochem. Z., 340, 243-262.

MATSUHASHI M., MATSUHASHI S., LYNEN F., 1964b. Zur biosynthese der Fettsäuren. V. Die Acetyl-CoA-Carboxylase aus Rattenleber und ihre Aktivierung durch Citronensäure. Biochem. Z., 340, 263-289.

MUTO Y., GIBSON D. M., 1970. Selective dampening of lipogenic enzymes of liver by exogenous polyinsaturated fatty acids. Biochem. biophys. Res. Comm., 38, 9-15.

NAKANISHI S., NUMA S., 1970. Purification of rat liver acetyl coenzyme A carboxylase and immunochemical studies on its synthesis and degradation. Eur. J. Biochem., 16, 161-173.

NESTEL P., AUSTIN W., FOWMAN C., 1969. Lipoprotein lipase content and triglyceride fatty acids uptake in adipose tissue of rats of differing body weights. J. Lipid Res., 10, 383-387.

NILSSON-EHLE P., CARLSTROM S., BELFRAGE P., 1975. Rapid effects on lipoprotein lipase activity in adipose tissue of humains after carbohydrate and lipid intake. Time course and relation to plasma glycerol, triglyceride and insulin levels. Scand. J. clin. Lab. Invest., 35, 373-378.

NUMA S., MATSUHASHI M., LYNEN F., 1961. Zur Störung der Fettsäuresynthese bei Hunger and Alloxan-Diabetes. I. Fettsauresynthese in der Leber Normaler und hungernder Ratten. Biochem. Z., 334, 203-217.

NUMA S. E., RINGELMANN E., LYNEN F., 1964. Zur biochemischen Funktion des Biotins. VIII. Die Bindung der Kohlensäure in der carboxylierten Acetyl-CoA-Carboxylase. Biochem., Z., 340, 228-242.

NUMA S., NAKANISHI S., HASHIMOTO T., IRITANI N., OKAZAKI T., 1970. Role of acetyl coenzyme A carboxylase in the control of fatty acid synthesis. Vitam. Horm., 28, 213-243.

PERET J., CHANEZ M., PASCAL G., 1976a. Schedule of protein ingestion and circadian rythm of certain hepatic enzyme activities involved in glucose metabolism in the rat. Nutr. Metab., 20, 143-157.

PERET J., CHANEZ M., PASCAL G., 1976b. Taux de protéines dans la ration et variations circadiennes des activités enzymatiques impliquées dans le métabolisme des glucides et dans la lipogenèse chez le rat mâle. J. Physiol. Paris, 72, 683-696.

RADOMSKI M., ORME T., 1971. Response of lipoprotein lipase in various tissues to cold exposure. Amer. J. Physiol., 220, 1852-1856.

RAULT C., FRUCHART J., DEWAILLY J., JAILLARD J., SEZILLE G., 1974. Experimental studies on the regulation of myocardial and adipose tissue lipoprotein lipase activities in the rat. Biochem. biophys. Res. Commun., 59, 160-166.

ROBINSON D. S., 1970. The function of the plasma triglycerides in fatty acid transport. Comp. Biochem., 18, 51-116.

SHOTZ M., GARFINKEL A., 1972. Effect of nutrition on species of LPL. Biochim. biophys. Acta, 270, 470-472.

TAYLOR C. B., BAILLEY E., BARTLEY W., 1967. Changes in hepatic lipogenesis during development of rat. Biochem. J., 105, 717-722.

VAGELOS P. R., ALBERTS A. W., MARTIN D. B., 1963. Studies on the mechanism of activation of acetyl coenzyme A carboxylase by citrate. J. biol. Chem., 238, 533-540.

VOLPE J. J., MARASA J. C., 1975. Hormonal regulation of fatty acid synthefase acetyl-CoA-carboxylase and fatty acid synthesis in mamalian adipose tissue and liver. Biochem. biophys. Acta, 380, 454-472.

VRANA A., FABRY P., KAZDOVA L., 1974. Lipoprotein lipase activity in heart diaphragm and adipose tissue in rats fed various carbohydrates. Nutr. Metabol., 17, 282-288. 
WAITE M., WAKIL S. J., 1963. Studies on the mechanism of action of acetyl-coenzyme A-carboxylase. J. biol. Chem., 238, 77-80 and 81-90.

WAKIL S. J., TITCHENER E. B., GIBSON D. M., 1958. Evidence for the participation of biotin in the enzymatic synthesis of fatty acids. Biochem. Biophys. Acta, 29, 225-226.

WAKIL S. J., 1958. A malonic acid derivation as an intermediate in fatty acid synthesis. J. amer. chem. Soc., 80, 6465.

WEISENBURG-DELORME C. L., HARRIS K. L., 1975. Effects of diet on lipoprotein lipase activity in the rat. J. Nutr., 105, 447-451. 